\title{
MAPEAMENTO GEOLÓGICO DE PORÇÃO DA BORDA NORTE DA BACIA DO ARARIPE, NORDESTE DO BRASIL
}

\author{
Cláudio Ângelo da Silva Neto ${ }^{1}$ \\ Letycia Oliveira Venancio ${ }^{2}$ \\ Dominick Sávio Rocha Cunha ${ }^{1}$ \\ Eduardo Ernesto Uvula ${ }^{1}$ \\ Nildo Cassul Miranda ${ }^{3}$ \\ Cynthia Romariz Duarte ${ }^{4}$ \\ 10.18190/1980-8208/estudosgeologicos.v29n2p79-94 \\ ${ }^{1}$ Mestrando do Programa de Pós-Graduação em Geologia - UFC, \\ claudioasn@gmail.com; dominick@alu.ufc.br; eduardouvula@yahoo.com.br. \\ ${ }^{2}$ Mestranda do Programa de Pós-Graduação em Geociências - UNICAMP, \\ letycia.venancio@hotmail.com. \\ ${ }^{3}$ Graduado(a) em Geologia - UFC,; dominick@alu.ufc.br; eduardouvula@yahoo.com.br; \\ nildomiranda29@gmail.com. \\ ${ }^{4}$ Docente do Departamento de Geologia - UFC, cynthia.duarte@ufc.br.
}

\section{RESUMO}

Em função do interesse científico e industrial, a Bacia do Araripe é constante alvo de pesquisas. A borda norte da bacia, por apresentar menor produção de gipsita e calcário para a construção civil, ainda carece de trabalhos em maior escala de detalhe. Neste contexto, este trabalho apresenta os resultados do mapeamento geológico em escala 1:25.000 de uma porção da borda norte da Bacia do Araripe, no Nordeste do Brasil, entre os municípios de Nova Olinda e Santana do Cariri, estado do Ceará. Durante o desenvolvimento do mapeamento geológico foram identificadas seis unidades litoestratigráficas, uma delas pertencentes ao embasamento da bacia formado por rochas gnáissicas com foliação de alto ângulo de trend NE-SW, sugerindo influência do Lineamento Patos na sua estruturação. As unidades sedimentares incluem a Formação Mauriti, composta por orto e paraconglomerados de ambiente deposicional fluvial entrelaçado, com fluxo unidirecional para NE; a Formação Crato, composta por calcários laminados, margas, folhelhos e arenitos, possui marcas de raízes em geometria de rede, implicando em um ambiente deposicional próximo à borda do paleolago, com exposição subaérea; a Formação Romualdo, composta por arenitos e folhelhos; a Formação Exu, composta por arenitos; e os depósitos aluviais constituídos por terrenos argilosos. De forma geral, a área de estudo apresentou sequências típicas do empilhamento estratigráfico da Bacia do Araripe. A presença de fraturas preenchidas por calcita e texturas indicativas de sismitos na Formação Crato sugerem uma possível influência tectônica no contexto deposicional deste conjunto de litotipos. Mudanças bruscas de direção das drenagens sugerem possível influência neotectônica na área. $O$ mapa geológico desta porção da borda norte da Bacia do Araripe, contribui para um melhor entendimento de seu contexto deposicional e pós-deposicional e servindo como base para a execução de futuros trabalhos mais aprofundados na região.

Palavras chave: Mapeamento de Terrenos Sedimentares; Bacias Interiores do Nordeste; Ambientes Deposicionais; Estratigrafia. 


\begin{abstract}
Due to the scientific and industrial interest, the Araripe Basin is a constant target of research. The northern border of the basin, due to its lower production of gypsum and limestone for civil construction, still lacks works on a larger scale of detail. In this context, this paper presents the results of a 1:25,000 scale geological mapping of a portion of the northern border of the Araripe Basin, in Northeastern Brazil, between the cities of Nova Olinda and Santana do Cariri, state of Ceará. Through the applied methodology, six lithostratigraphic units were, one of them belonging to the basin basement formed by gneissic rocks with high angle foliation trend NE-SW, suggesting influence of the Patos Lineament in its structure. Sedimentary units include the Mauriti Formation, consisting of ortho and para-conglomerates of intertwined fluvial depositional environment with unidirectional flow to the NE; The Crato Formation, composed of laminated limestones, marl, shales and sandstones, has root marks in lattice geometry, implying a depositional environment near the palaeo-lake border, with subaerial exposure; the Romualdo Formation, composed of sandstones and shales; the Exu Formation, composed of sandstones; and alluvial deposits consisting of clayey land. In general, the study area showed typical stratigraphic stacking sequences of the Araripe Basin. The presence of calcite-filled fractures and textures indicative of seismites in the Crato Formation suggest a possible tectonic influence on the depositional context of this set of lithotypes. Sudden changes in drainage direction suggest a possible neotectonic influence on the area. The activity was successful in characterizing the northern edge portion of the Araripe Basin, contributing to a better understanding of its depositional and post-depositional context and serving as a basis for further in-depth work in the region.
\end{abstract}

Keywords: Sedimentary Terrains Mapping; Northeast Interior Basins; Depositional Environments; Stratigraphy.

\section{INTRODUÇÃO}

A Bacia do Araripe desperta o interesse científico desde o início do século XIX, principalmente devido ao seu importante conteúdo fossilífero (Chagas, 2006). Ela é uma das bacias sedimentares interiores mais importantes do nordeste brasileiro e possui uma grande influência no âmbito da economia local, regional e nacional, com destaque para o aspecto mineral da intensa produção de gipsita e calcário para a construção civil (Silva et al., 2017).

Em função do interesse apresentado a esta bacia pelo setor industrial, se faz necessário o mapeamento geológico de detalhe das unidades que a formam. Porém, apesar do potencial econômico da exploração mineral na área, percebe-se um déficit de estudos com este enfoque, em especial na sua porção cearense.

Em 2017, o Serviço Geológico do Brasil (CPRM) executou no noroeste do estado de Pernambuco o Projeto Gipsita na Bacia do Araripe, que teve como objetivo a revisão das unidades geológicas na área em estudo, com foco para a Formação Ipubi. Os resultados foram apresentados em sete folhas geológicas na escala 1:50.000 (Simões, Araripina, Monte Santo, Curral, Novo do Piauí, Morais, Ipubi, Trindade) (Barros et al., 2017).

Já a borda norte da bacia, apesar de também possuir boa exposição do Grupo Santana e cavas de exploração de calcário e gipsita, não foi contemplada 
por mapeamentos em maior escala de detalhe, restringindo-se ainda a produtos em escala regional de 1:500.000 (Cavalcante et al., 2003), sem diferenciação do Grupo Santana.

Esta lacuna foi um fator motivador para realizar o mapeamento geológico em escala de detalhe de uma pequena porção da borda norte da Bacia do Araripe, entre os municípios de Nova Olinda e Santana do Cariri (Fig. 1), e verificar se os seus resultados justificam outros trabalhos de detalhamento geológico na borda norte da Bacia do Araripe, seja por interesse científico ou econômico. Como premissa, foi escolhida uma área de $24 \mathrm{~km}^{2}$ que contemplasse necessariamente o Grupo Santana, empregando uma metodologia de campo que proporcionasse sua melhor caracterização, envolvendo: descrição dos litotipos encontrados na área; identificação de estruturas sedimentares; análise faciológica das unidades litoestratigráficas; aquisição de medidas estruturais indicadoras de acamamentos, paleocorrentes e foliações; e determinação de possíveis paleoambientes.

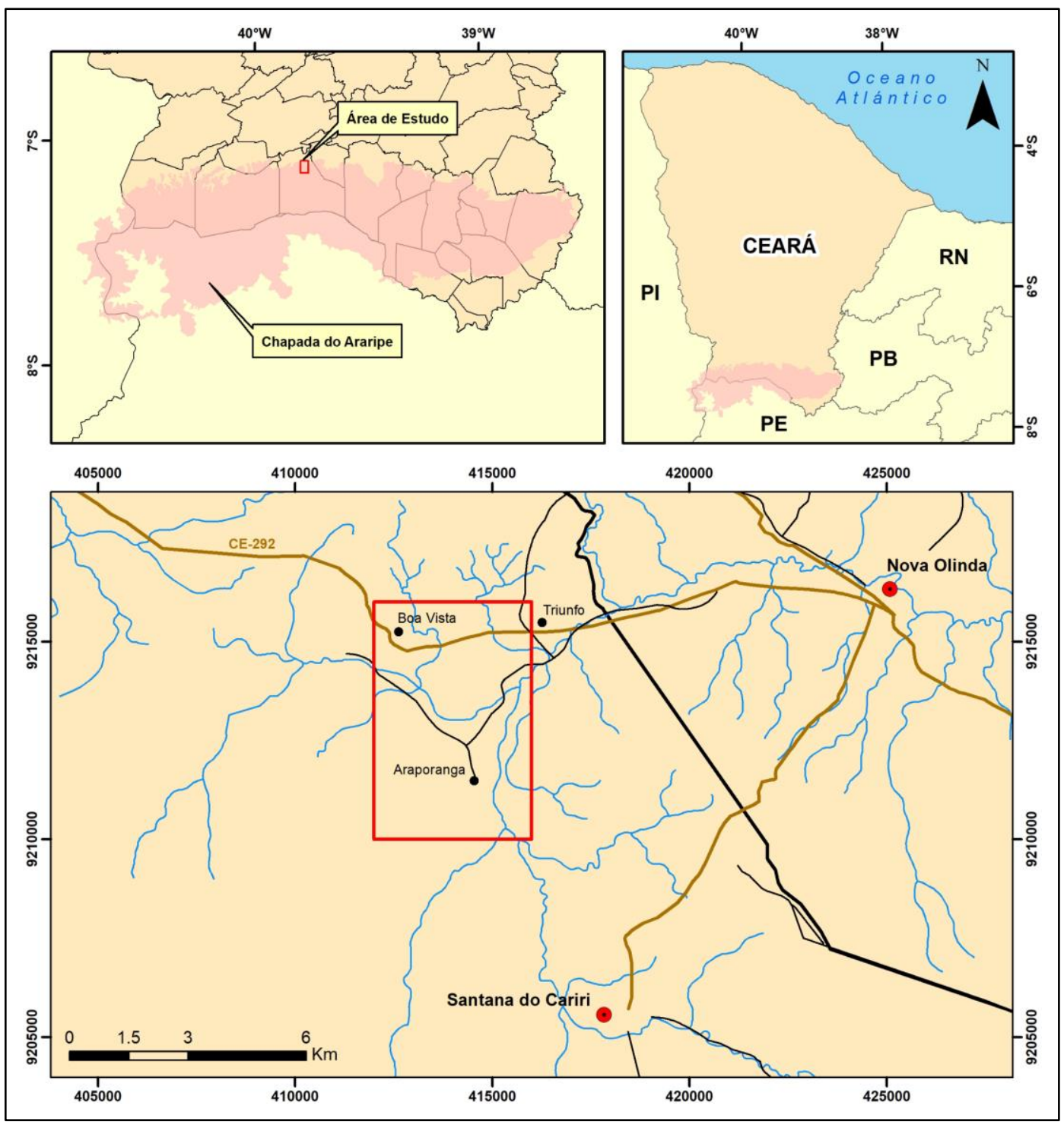

Figura 1 - Localização da área em estudo. 


\section{METODOLOGIA}

A execução das atividades deste trabalho foi dividida em três etapas. Um reconhecimento prévio da área a ser estudada foi feito a partir das imagens fornecidas gratuitamente pelo programa Google Earth Pro $^{\circledR}$, utilizando seus produtos com maior resolução espacial para identificar, principalmente, estradas e drenagens presentes, auxiliando a produção do mapa de localização e os consequentes caminhamentos da etapa de campo. Ainda nesta primeira abordagem, a folha topográfica Santana do Cariri SB.24-Y-D-II (SUDENE, 1969) também subsidiou um melhor reconhecimento da área.

A etapa de campo contemplou a execução de caminhamentos a fim de identificar e descrever os diferentes litotipos presentes, definindo os possíveis contatos entre eles. Tomou-se preferência por caminhamentos em drenagens que dissecam o relevo perpendicularmente ao gradiente altimétrico, possibilitando uma melhor exposição das rochas, especialmente no Grupo Santana. Ao todo, foram descritos 51 pontos, envolvendo a observação de aspectos como mineralogia, granulometria, cor, arredondamento, esfericidade, grau de seleção, geometria interna e externa, estruturas sedimentares e fósseis. Além disso, medidas estruturais de acamamento, paleocorrente e foliação (esta última nas rochas correspondentes ao embasamento da bacia) também foram obtidas.

Posteriormente, os dados adquiridos em campo foram organizados e interpretados, a fim de correlacionar as fácies da geologia local e definir possíveis condições paleoambientais que condicionaram a deposição dos litotipos encontrados. Os produtos finais consistiram do relatório descritivo e interpretativo de campo; da integração dos litotipos e dados estruturais em mapa geológico em escala de semi-detalhe (1:25.000); e de seção geológica representativa da área, com exagero vertical de 5 vezes, destacando a variação topográfica e as relações de contato entre as unidades geológicas mapeadas (Fig. 2).

\section{GEOLOGIA REGIONAL}

A Bacia do Araripe é a mais extensa bacia interior do nordeste brasileiro (Assine, 2007) e de acordo com Brito Neves et al. (2000) encontrase implantada em terrenos précambrianos da Zona Transversal da Província Borborema, englobando partes dos estados de Ceará, Pernambuco e Piauí. 


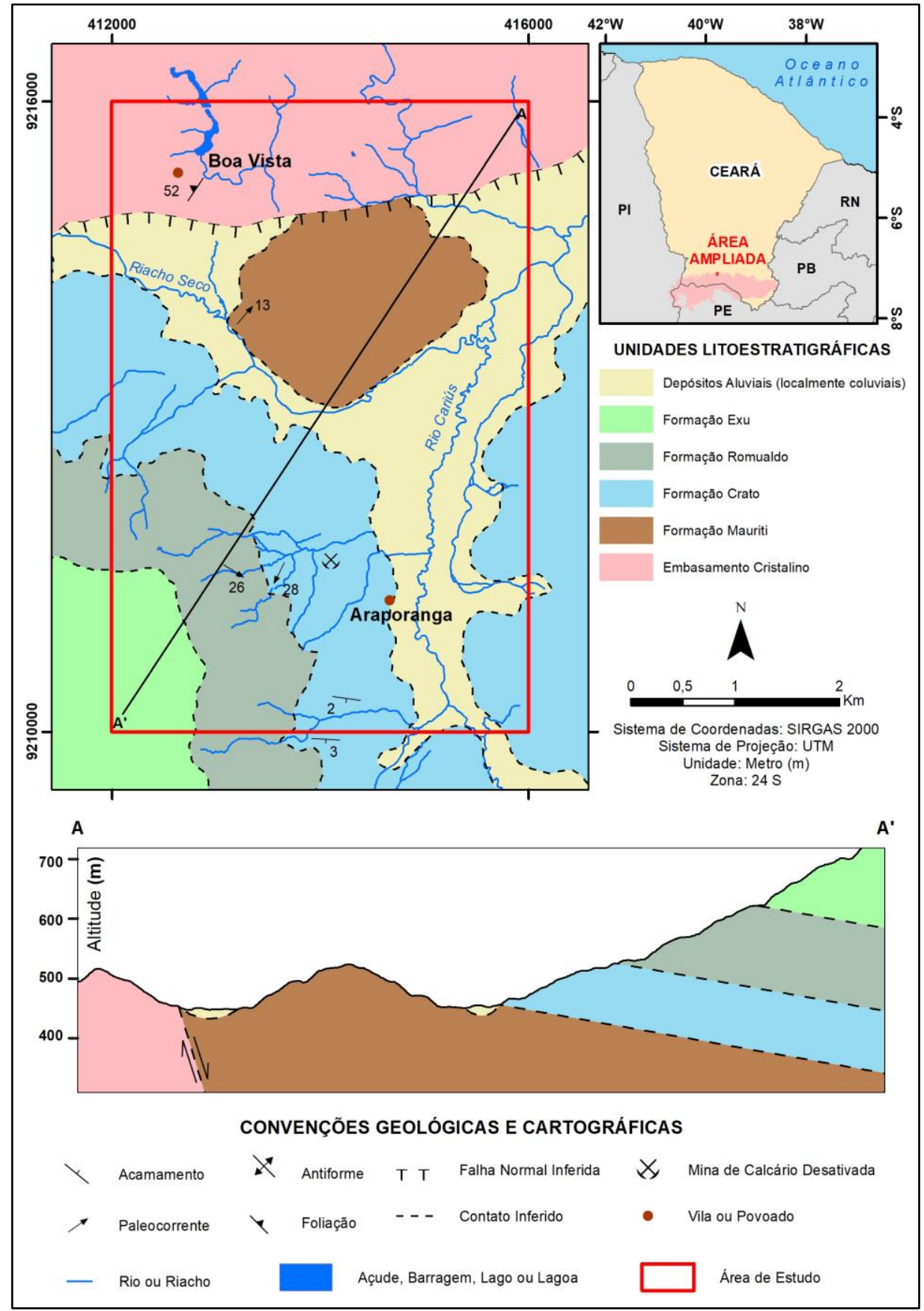

Figura 2 - Mapa geológico proposto para a área em estudo, com seção geológica representativa.

É dividida estratigraficamente em sequências, da base para o topo, sendo elas nomeadas: Sequência Paleozóica,
Supersequência

Pré-Rifte, Supersequência Rifte e Supersequência Pós Rifte I e II (Tabela 1). 
Tabela 1 - Coluna estratigráfica da Bacia do Araripe. Fonte: adaptado de Assine (2007) e Assine et al. (2014).

\begin{tabular}{|c|c|c|c|c|c|}
\hline \multirow[t]{2}{*}{ PERÍODO } & \multirow[t]{2}{*}{ TECTÔNICA } & \multicolumn{2}{|c|}{$\begin{array}{c}\text { UNIDADES } \\
\text { ESTRATIGRÁFICAS }\end{array}$} & \multirow{2}{*}{$\begin{array}{c}\text { AMBIENTE } \\
\text { DEPOSICIONAL }\end{array}$} & \multirow{2}{*}{$\begin{array}{l}\text { COMPOSIÇÃO } \\
\text { LITOLÓGICA }\end{array}$} \\
\hline & & GRUPO & FORMAÇÃO & & \\
\hline \multirow{9}{*}{ Mesozoico } & \multirow[b]{2}{*}{ Pós-Rifte II } & \multirow[b]{2}{*}{ Araripe } & Exu & Fluvial & $\begin{array}{l}\text { Arenitos grossos a } \\
\text { conglomeráticos }\end{array}$ \\
\hline & & & Araripina & Aluvial & $\begin{array}{c}\text { Arenitos finos e } \\
\text { lamitos intercalados a } \\
\text { arenitos grossos }\end{array}$ \\
\hline & \multirow{4}{*}{ Pós-Rifte I } & \multirow{4}{*}{ Santana } & Romualdo & $\begin{array}{l}\text { Costeiro a } \\
\text { plataformal }\end{array}$ & $\begin{array}{c}\text { Arenitos } \\
\text { interestratificados } \\
\text { com folhelhos }\end{array}$ \\
\hline & & & Ipubi & Lacustre a costeiro & $\begin{array}{c}\text { Camadas } \\
\text { descontínuas de } \\
\text { gipsita associadas a } \\
\text { folhelhos }\end{array}$ \\
\hline & & & Crato & $\begin{array}{l}\text { Lacustre raso a } \\
\text { profundo }\end{array}$ & $\begin{array}{c}\text { Calcários laminados } \\
\text { intercalados a } \\
\text { arenitos, margas e } \\
\text { folhelhos }\end{array}$ \\
\hline & & & Barbalha & Fluvio-lacustre & $\begin{array}{l}\text { Arenitos com } \\
\text { intercalações de } \\
\text { folhelhos }\end{array}$ \\
\hline & Rifte & \multirow{3}{*}{$\begin{array}{c}\text { Vale } \\
\text { do Cariri }\end{array}$} & Abaiara & Fluvio-lacustre & $\begin{array}{l}\text { Folhelhos, siltitos e } \\
\text { arenitos finos }\end{array}$ \\
\hline & \multirow{2}{*}{ Pré-Rifte } & & Missão Velha & Fluvial entrelaçado & $\begin{array}{l}\text { Arenitos quartzosos } \\
\text { e/ou feldspáticos }\end{array}$ \\
\hline & & & Brejo Santo & Lacustre & $\begin{array}{c}\text { Folhelhos e lamitos } \\
\text { vermelhos }\end{array}$ \\
\hline Paleozoico & $\begin{array}{c}\text { Sinéclise } \\
\text { Intracratônica }\end{array}$ & & Mauriti & Fluvial entrelaçado & $\begin{array}{c}\text { Arenitos imaturos e } \\
\text { conglomerados }\end{array}$ \\
\hline $\begin{array}{c}\text { Pré- } \\
\text { Cambriano } \\
\end{array}$ & \multicolumn{5}{|c|}{ Embasamento } \\
\hline
\end{tabular}

A sequência Paleozóica é constituída por uma única unidade litoestratigráfica, denominada Formação Cariri por Beurlen (1962) em trabalhos mais recentes a Formação Cariri foi denominada Formação Mauriti, proposta por Gaspary e Anjos (1964) e adotada por Ponte e Appi (1990). Por conseguinte, neste trabalho a unidade será denominada de Formação Mauriti. De acordo com Assine (2007), a Supersequência PréRifte, é constituída pelas formações Brejo Santo e Missão Velha; Supersequência Rifte, correspondente à Formação Abaiara, Supersequência Pós-Rifte I, constituída pelas formações Barbalha e Santana; e
Supersequência Pós Rifte II constituída pelas formações Araripina e Exu.

Em nova subdivisão, Assine et al. (2014) propõem a adoção do Grupo Santana, constituído, da base para o topo, pelas formações Barbalha, Crato, Ipubi e Romualdo, sendo esta terminologia adotada neste trabalho.

\section{ASPECTOS DE CAMPO}

\section{Embasamento}

Localizado na porção norte da área em estudo, é constituído de gnaisses cujos bandamentos têm mineralogia essencial composta por quartzo, feldspato potássico e anfibólio, com 
granulação milimétrica a centimétrica. A rocha como um todo está milonitizada e apresenta veios pegmatíticos concordantes com a foliação (Fig. 3). A ausência de minerais aluminosos sugere um protólito ígneo para esta porção do embasamento.

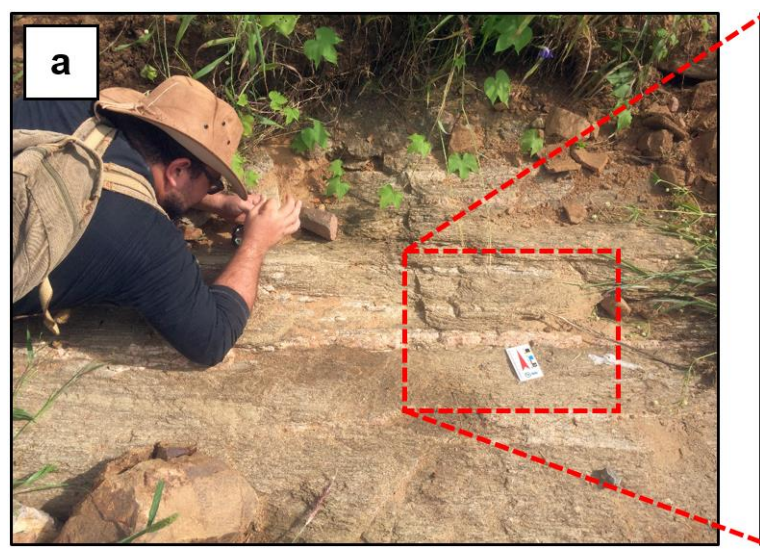

Figura 3 - (a) Afloramento do tipo lajedo, com gnaisses milonitizados recortados por veios pegmatíticos de feldspato potássico e quartzo concordantes com a foliação; (b) Visualização da diferença mineralógica e textural entre os gnaisses e os veios de feldspato potássico e quartzo.

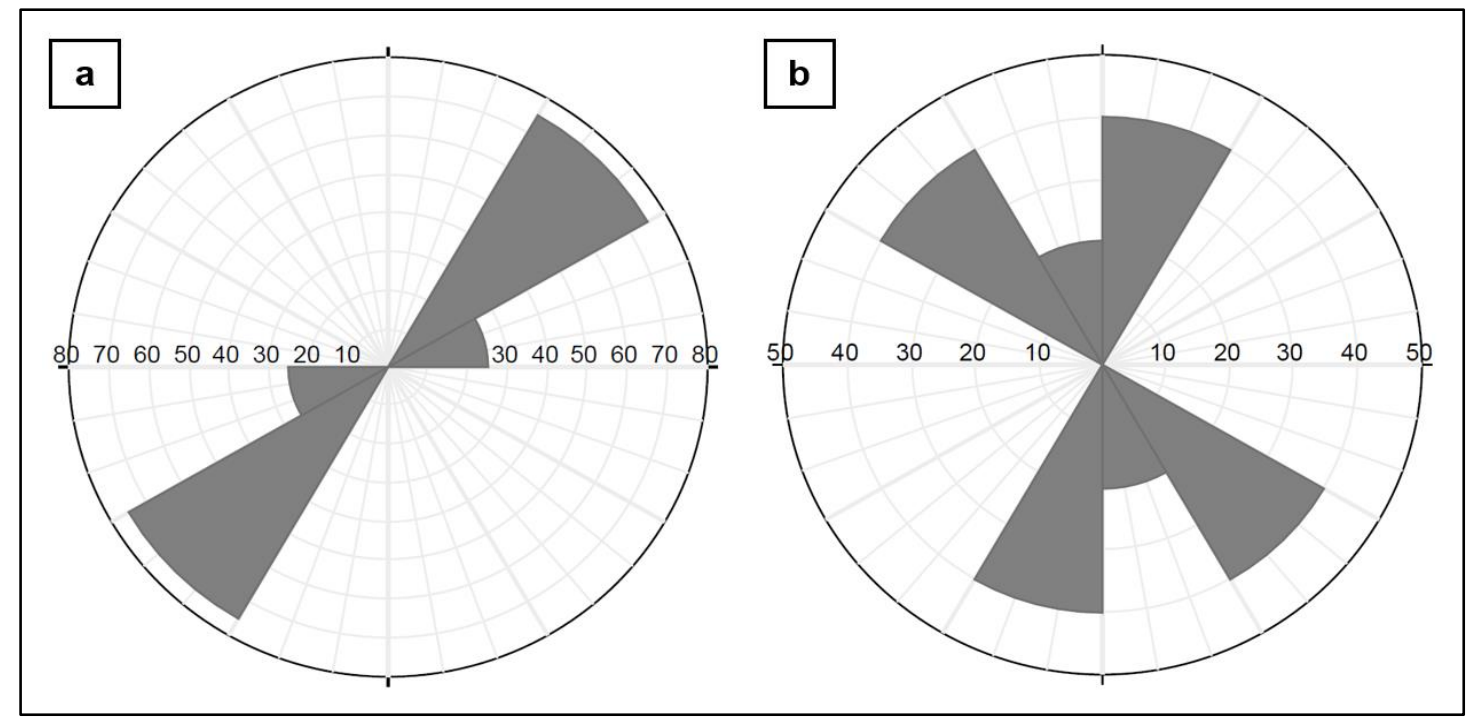

Figura 4 - Diagramas de Roseta representando os trends dos planos de foliação (a) e fraturas (b) presentes no embasamento da área. 


\section{Formação Mauriti}

Constituída de orto e paraconglomerados, com grãos arredondados a subarredondados variando da fração areia até matacão, por vezes com grande diferença entre a granulação da matriz e do arcabouço (Fig. 5). Apresenta estratificação cruzada acanalada com medida de paleocorrente $43 \mathrm{Az} / 13^{\circ}$, indicando fluxo unidirecional para NE. Este padrão de estrutura sedimentar sugere variação da energia das linhas de fluxo, este por vezes mais viscoso, indicando migração lateral de canal com eventos episódicos de maior energia, compatível com um ambiente deposicional fluvial entrelaçado (Fig. 6).
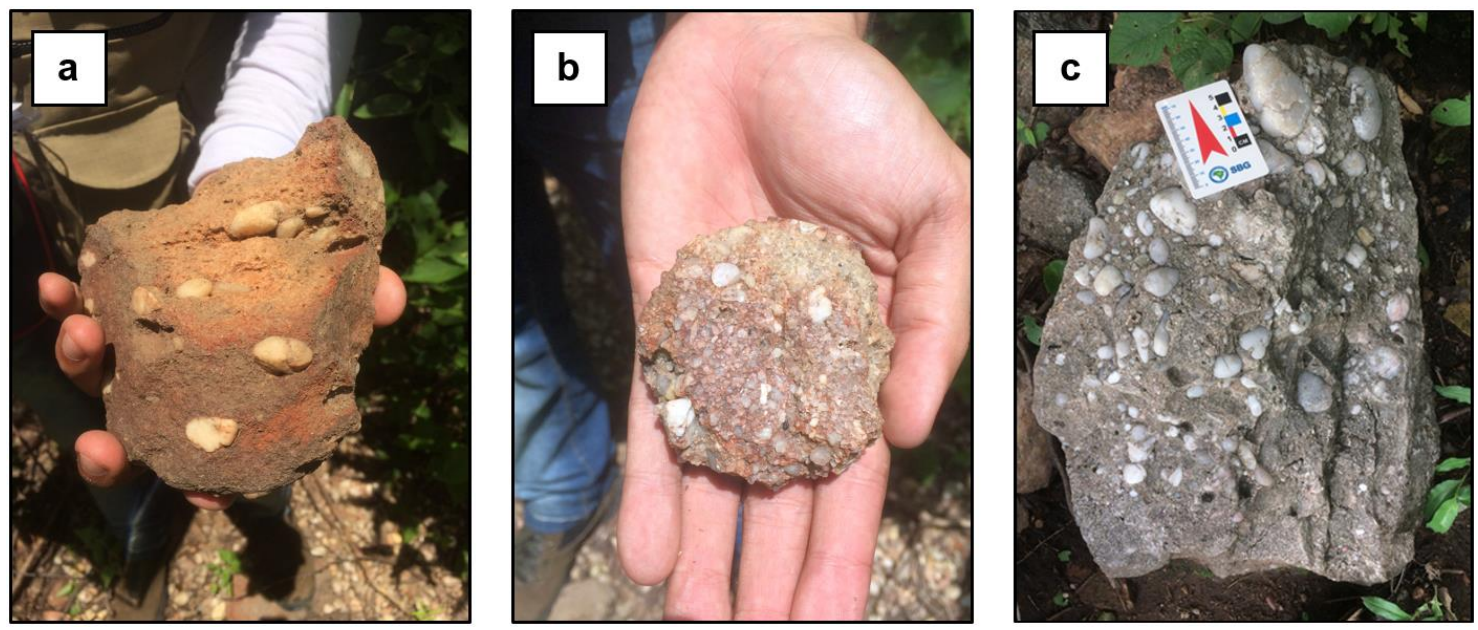

Figura 5 - (a) Fragmento de paraconglomerado com grãos de quartzo arredondados, relativamente orientados. Sugerindo uma organização sob fluxo de alta viscosidade com concentração em finos; (b) Fragmento de conglomerado melhor selecionado, com gradação de tamanhos de grãos-clastos; (c) Paraconglomerado evidenciando a capacidade do paleoambiente deposicional de transportar grãos de maior tamanho. Neste caso, clastos centimétricos de quartzo, não orientados, estão dispostos em uma matriz bem mais fina e mais homogênea, sugerindo um fluxo de alta viscosidade. 

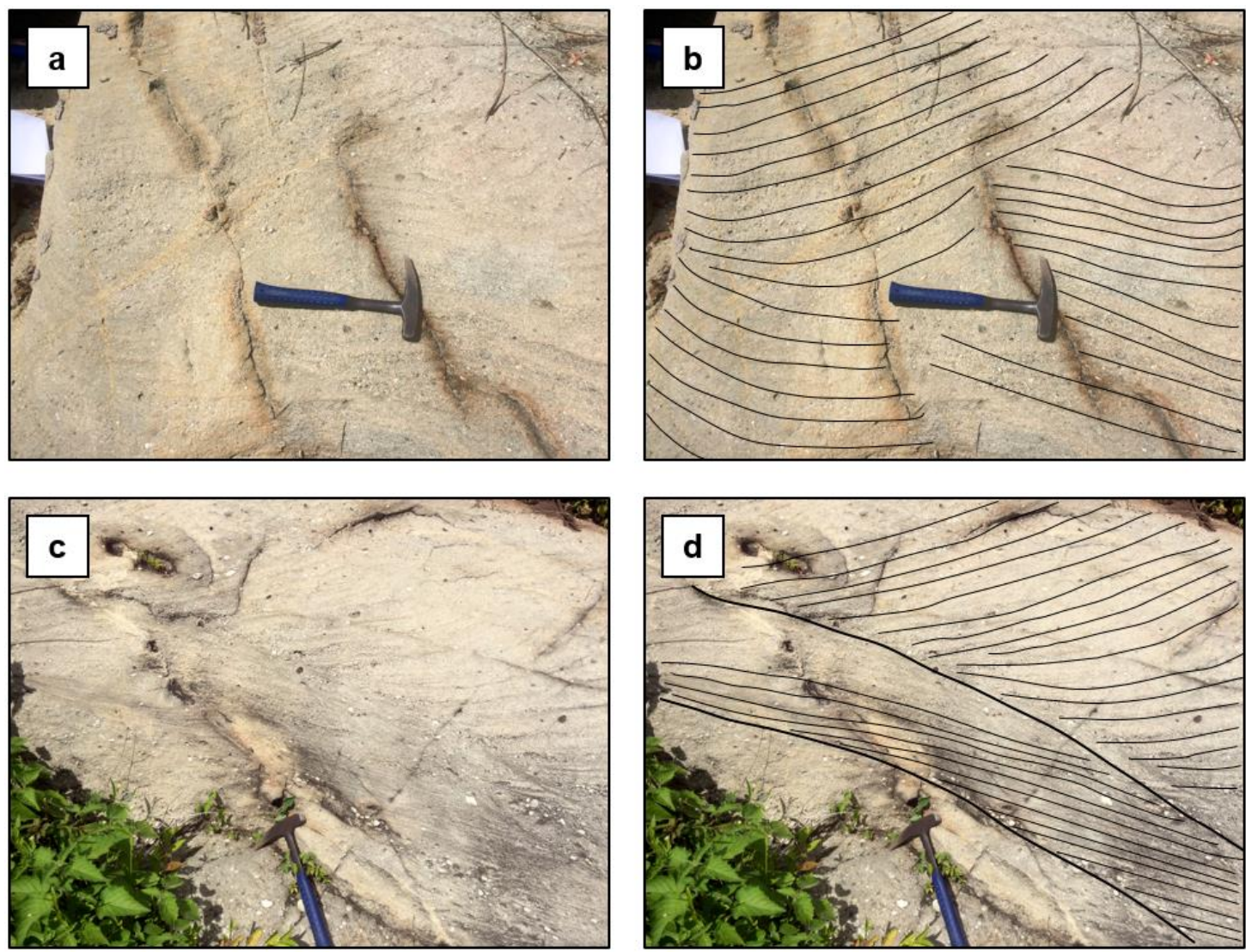

Figura 6 - Visão de topo de afloramento da Fm. Mauriti, com marcas de estratificações cruzadas festonadas, sugerindo a migração lateral de um canal fluvial, com interpretação (b) dos truncamentos entre as estruturas; (c) Visão lateral do mesmo afloramento, com a presença de estratificações cruzadas e dois possíveis limites de séries; aqui também. temos níveis conglomeráticos atestando modificação de energia (d), marcados pela segregação de grãos de quartzo que tendem a se concentrar nestas porções.

\section{Formação Crato}

Composta por calcários laminados de cores amarelo e cinza intercalados com níveis centimétricos a decimétricos de margas, folhelhos e arenitos (Figs. 7 e 8). Na área em estudo, a formação possui variações texturais e de estruturas internas, com porções contendo concreções lenticulares de até $15 \mathrm{~cm}$ concordantes com o acamamento, além de concreções silicificadas e concreções de calcita espática impura e micrítica em gretas (Figs. 9 e 10). Também foram identificadas marcas de raízes em geometria de rede, sugerindo um ambiente de deposição mais próximo à borda do paleolago, com exposição subaérea. 

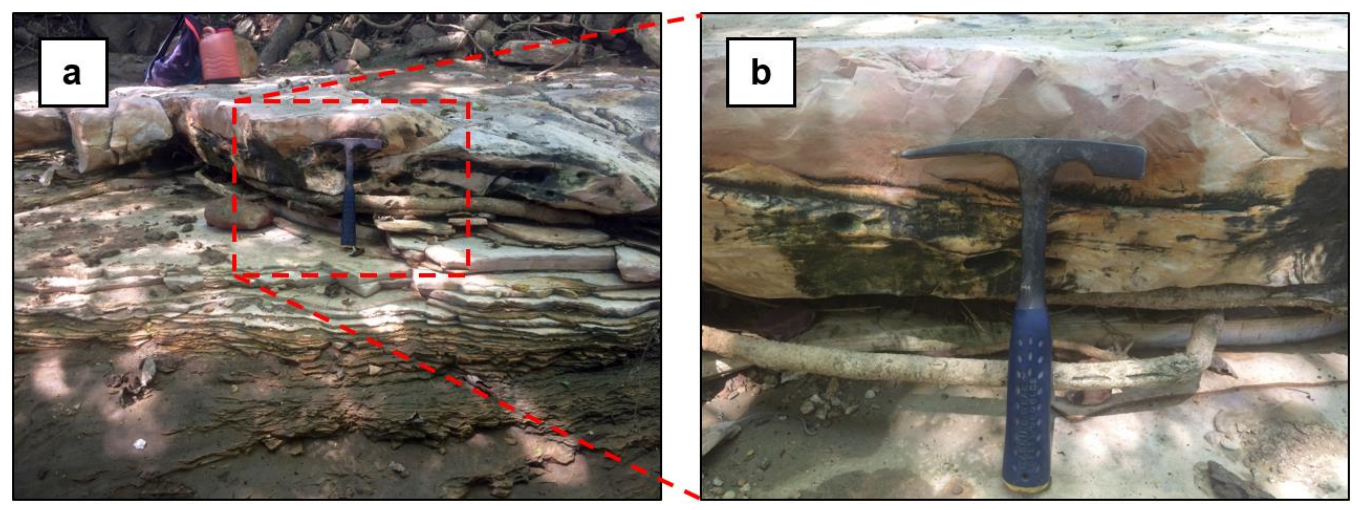

Figura 7 - Calcários laminados com intercalações de arenitos bastante silicificados e apresentando laminações plano-paralelas.
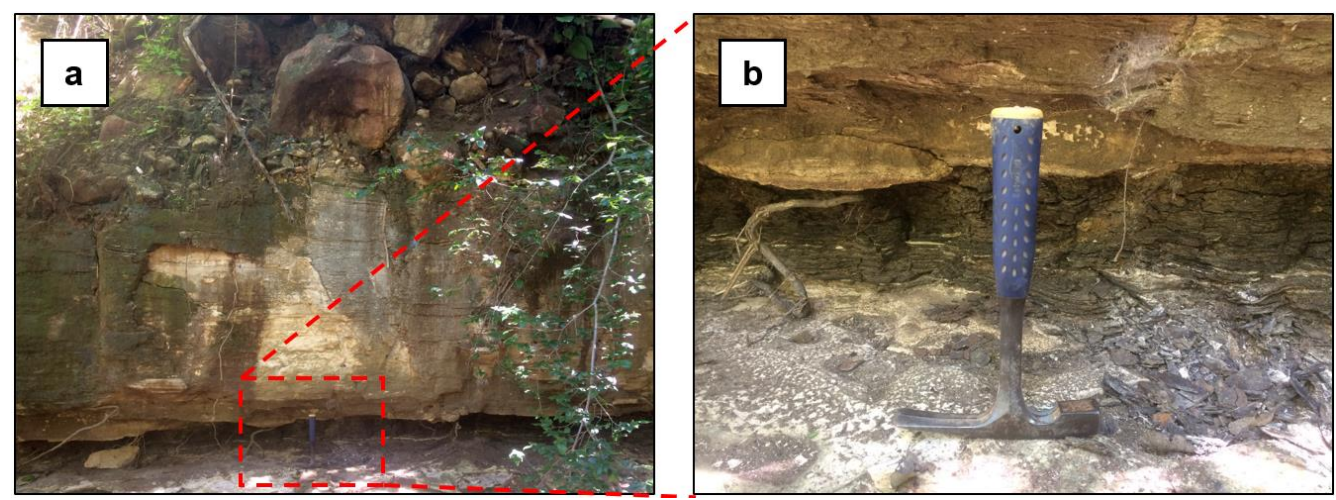

Figura 8 - Variação faciológica vertical típica na Formação Crato, com uma camada de folhelhos centimétrica sobreposta por uma camada métrica de calcário laminado.
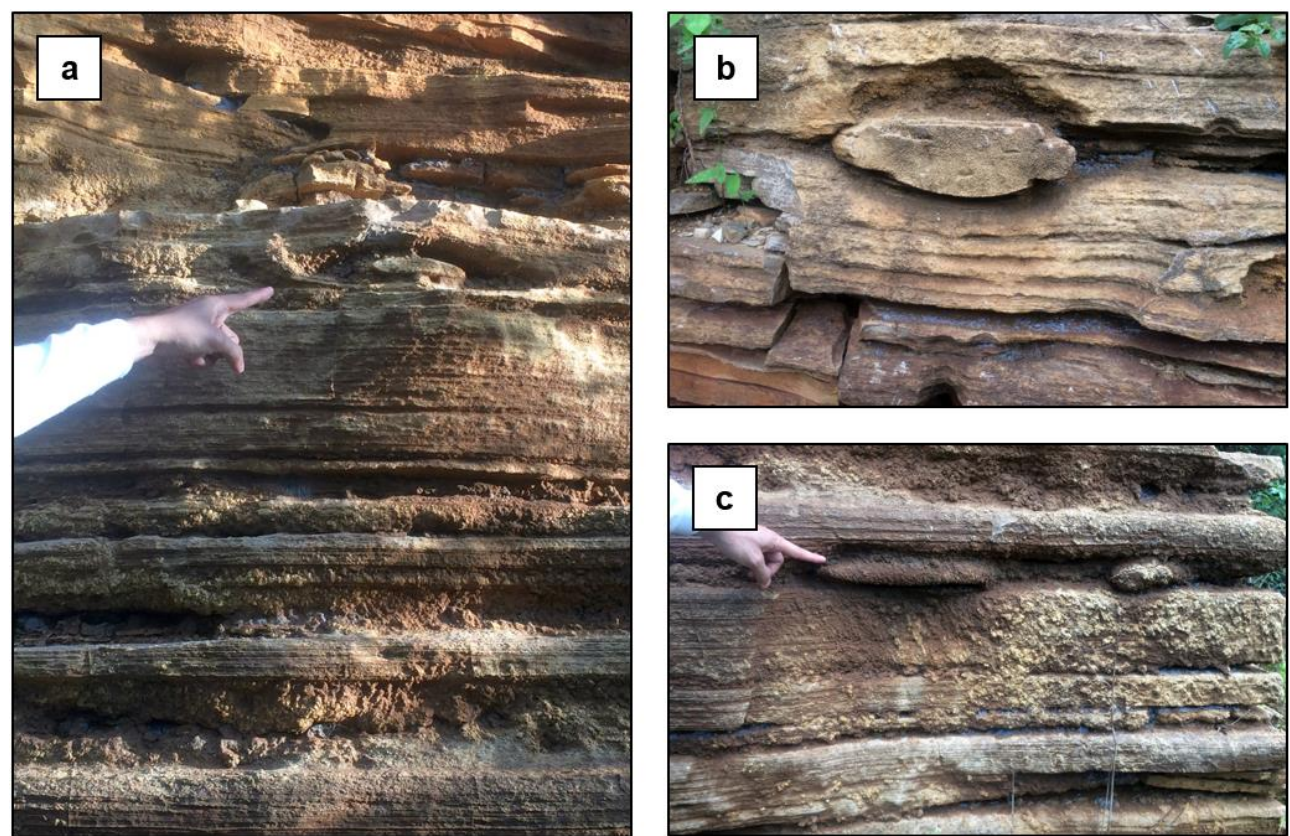

Figura 9 - Presença de concreções lenticulares, com até $15 \mathrm{~cm}$ no maior eixo, concordantes com o acamamento e aparentemente silicificadas, deformando as camadas de calcário laminado no seu entorno nos exemplos a, b e c. 

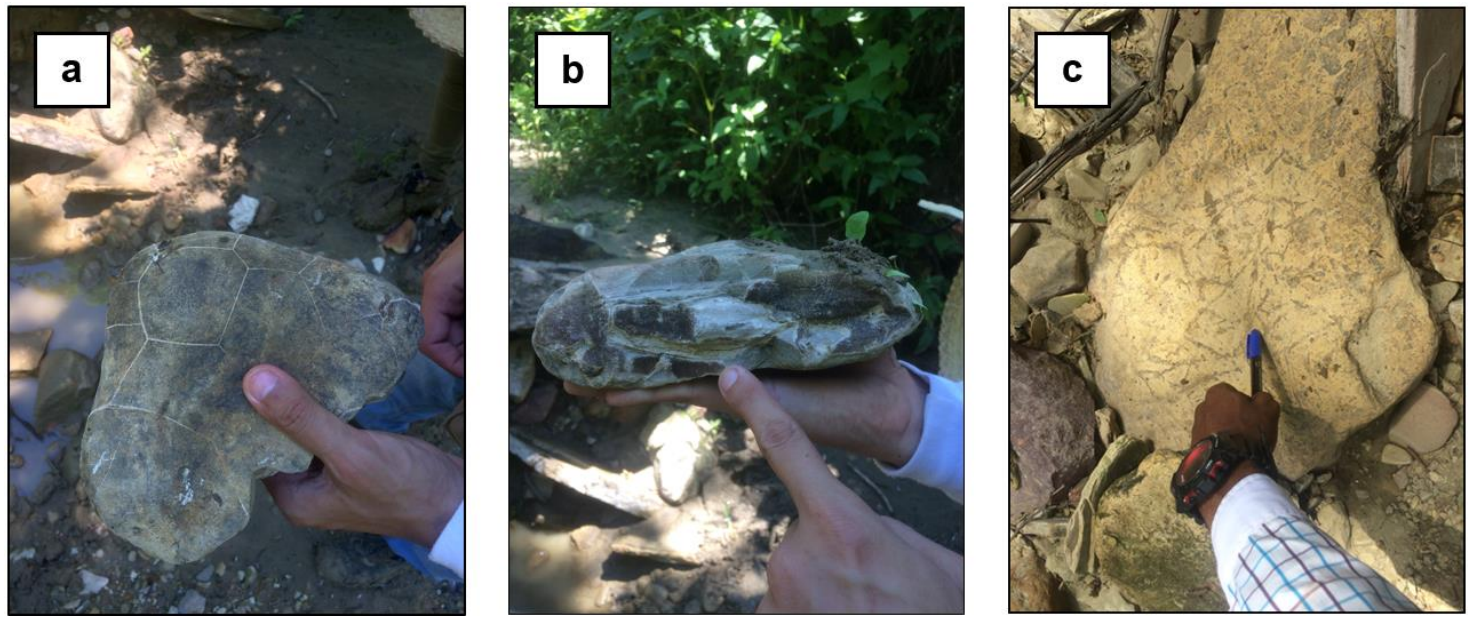

Figura 10 - Concreção de calcita espática impura e micrítica nas gretas (a, b); Fragmento de calcário laminado apresentando marcas de raízes em geometria de rede, possivelmente indicando que ele foi formado em uma borda do lago com exposição subaérea.

Foi constatada a presença de fraturas preenchidas por calcita, constituindo veios que podem indicar uma injeção em fendas induzida por sismos, sugerindo movimentação transcorrente e cominuição do material por diferença reológica (Fig. 11). Também foram identificados calcários com estruturas sugestivas de perturbações onduladas em sedimentos finos anteriormente plano-paralelos. Este tipo de deformação pode ser interpretado como um sismito, intercalado com arenitos bastante silicificados (Fig. 12).
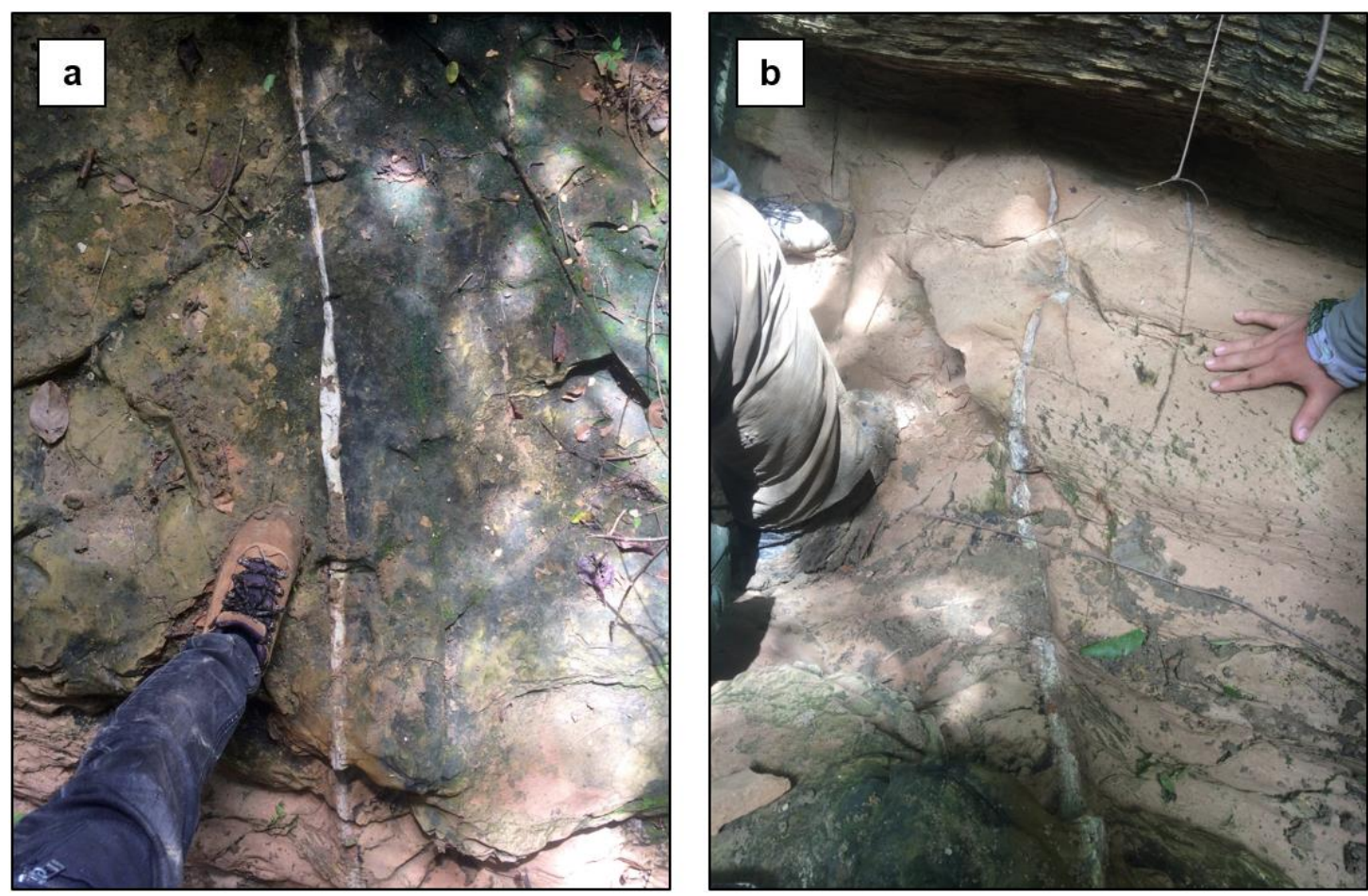

Figura 11 - Calcário laminado com fraturas formadas posteriormente e preenchidas por calcita. As duas fraturas têm direções $174^{\circ} \mathrm{Az}$ e $280^{\circ} \mathrm{Az}$. 
$\mathrm{Na}$ porção superior, foi identificada a ocorrência de calcários laminados com cimentação ferruginosa, relacionados ao último ciclo deposicional antes da Formação Ipubi, além de argilitos com nódulos de calcrete, com início de pedogênese. Medidas de acamamento indicaram um paleofluxo para sul, com média de $182^{\circ} \mathrm{Az} / 3^{\circ}$.

\section{Formação Romualdo}

Constituída por arenitos de granulação fina, com camadas tabulares de séries decimétricas de estratificação cruzada de base reta, com direções de paleocorrente $123 \mathrm{Az} / 26^{\circ}$ e $124 \mathrm{Az} / 26^{\circ}$. Também ocorrem camadas de folhelho de cor verde com porções de calcita segregada, tabular, com cerca de $50 \mathrm{~cm}$ de espessura (Figs. 13 e 14).

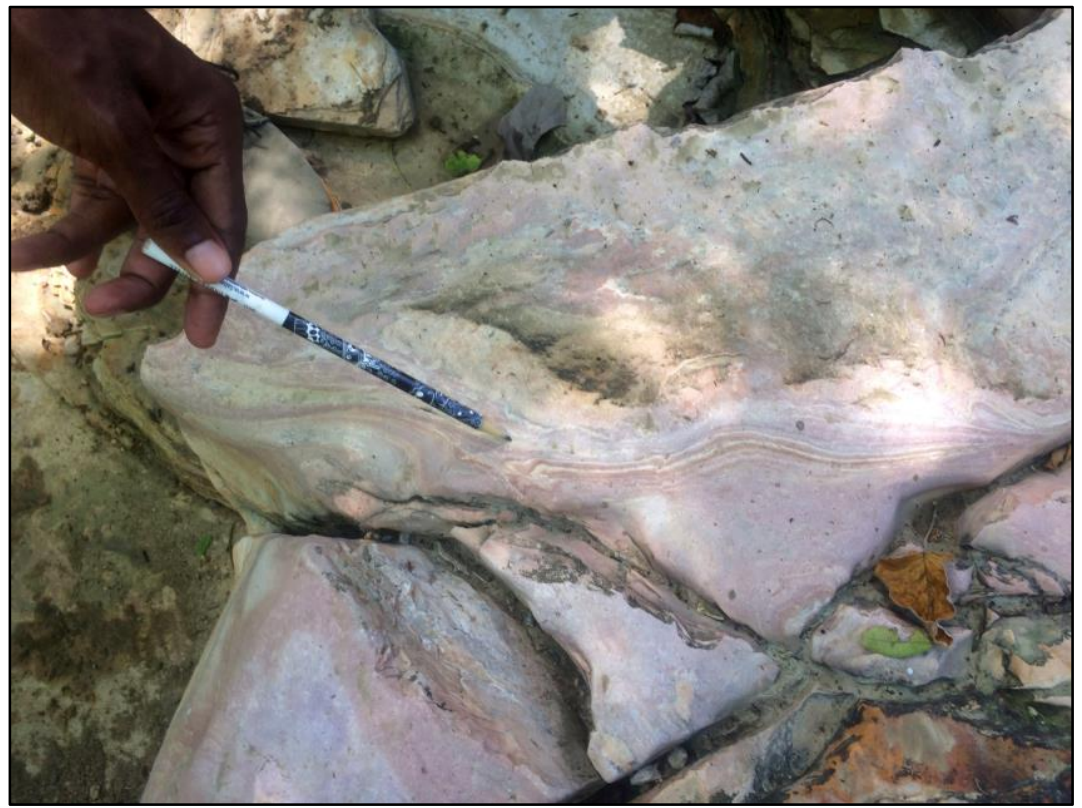

Figura 12 - Ocorrência de calcários laminados maciços e com laminações com indícios de sismitos.
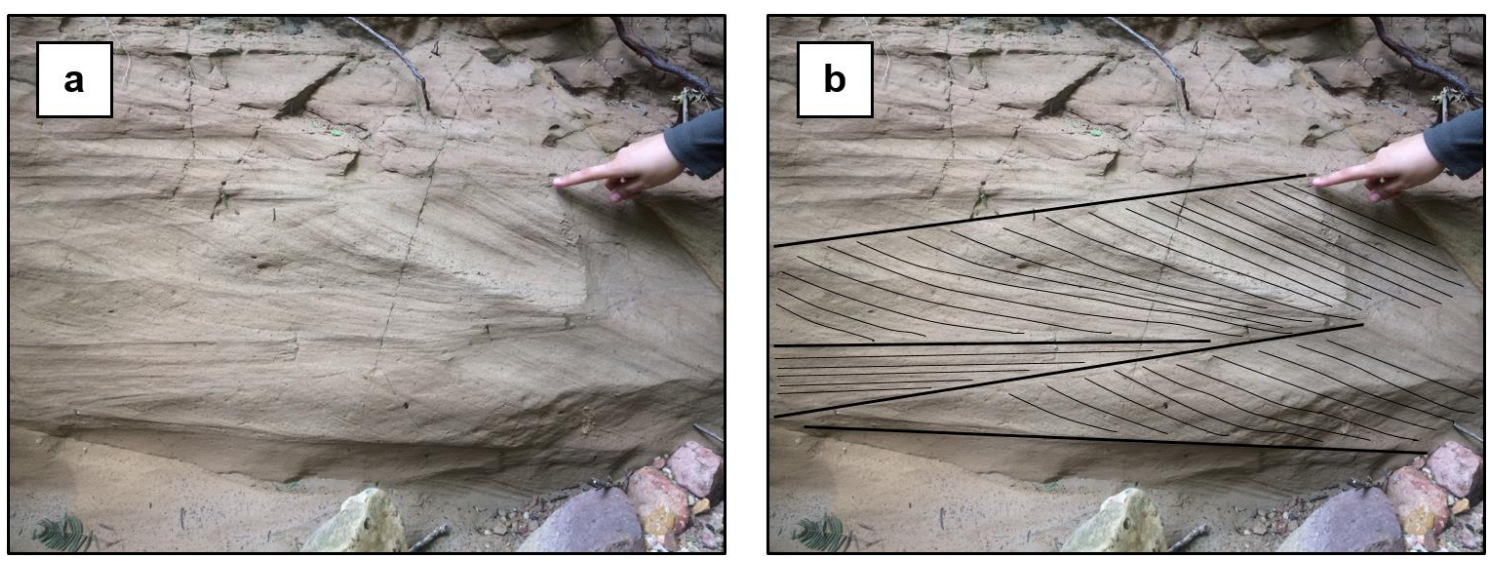

Figura 13 - Interpretação das estratificações cruzadas presentes na formação, com demarcação dos limites de série e variação do fluxo das paleocorrentes. A variação no mergulho das estratificações sugere uma variação no padrão de transporte ao longo do tempo, seja por mudança de energia ou variação lateral de canal. 


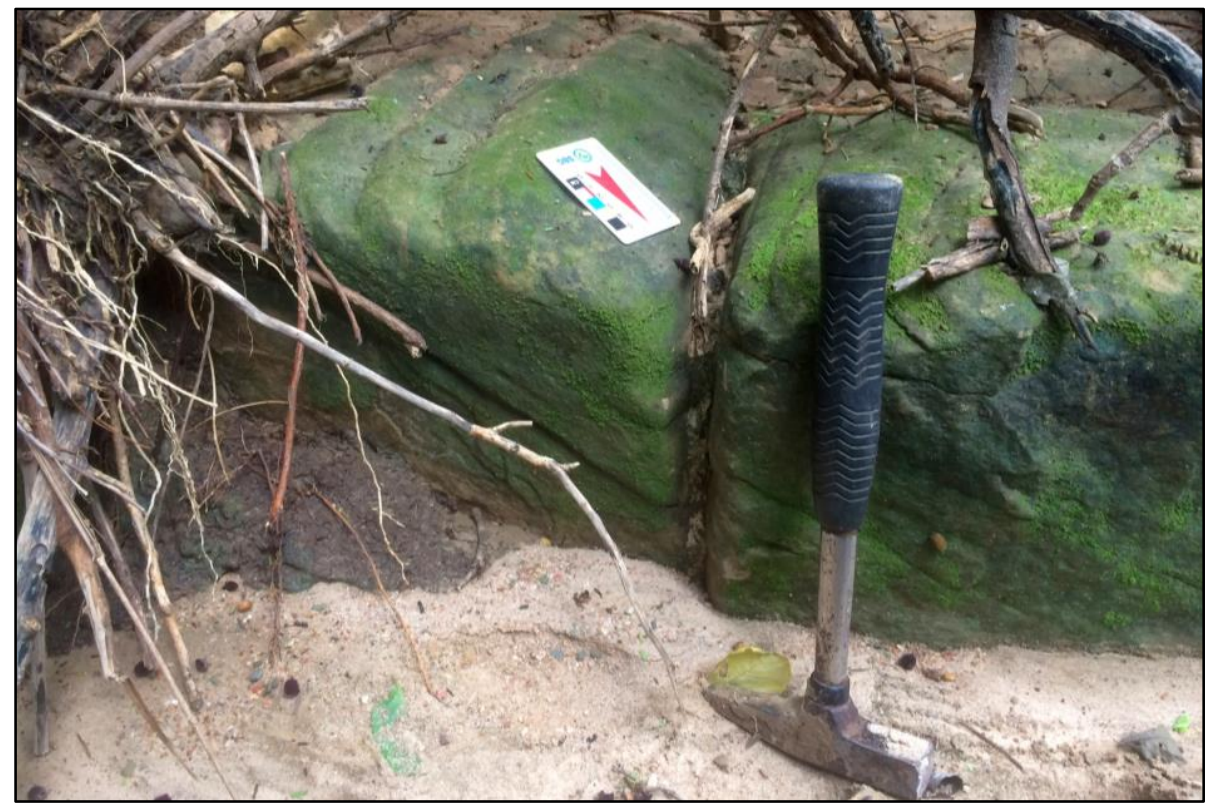

Figura 14 - Arenito de granulação fina com foreset das estratificações cruzadas bem definido, indicando paleocorrente $123 \mathrm{az} / 23^{\circ}$.

Também foram observados calcários com presença de óxi-hidróxido de ferro ocupando vazios com crescimento espático e matéria orgânica oxidada, além de silicificação com calcedônia e fragmentos de folhelho orgânico com ostracodas (Fig. 15).

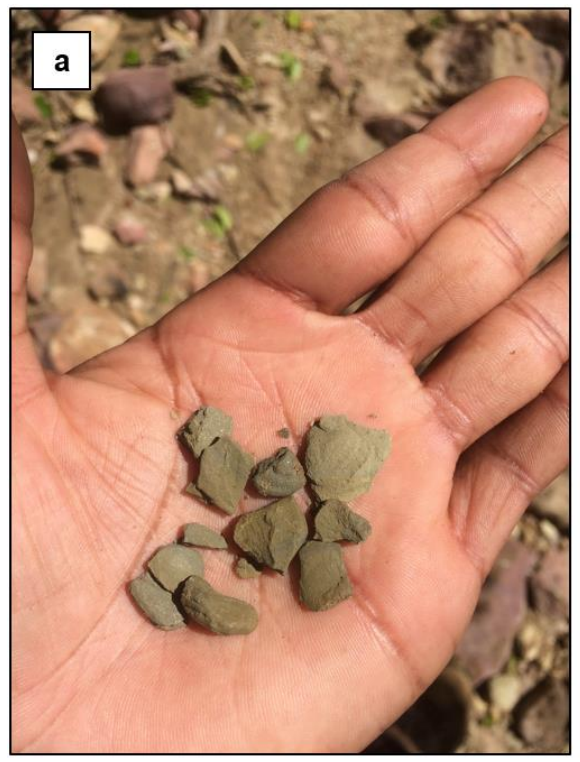

Na área em estudo, não foi possível identificar afloramentos da Formação Ipubi, embora a ocorrência de alguns fragmentos de gipsita possa indicar sua proximidade.

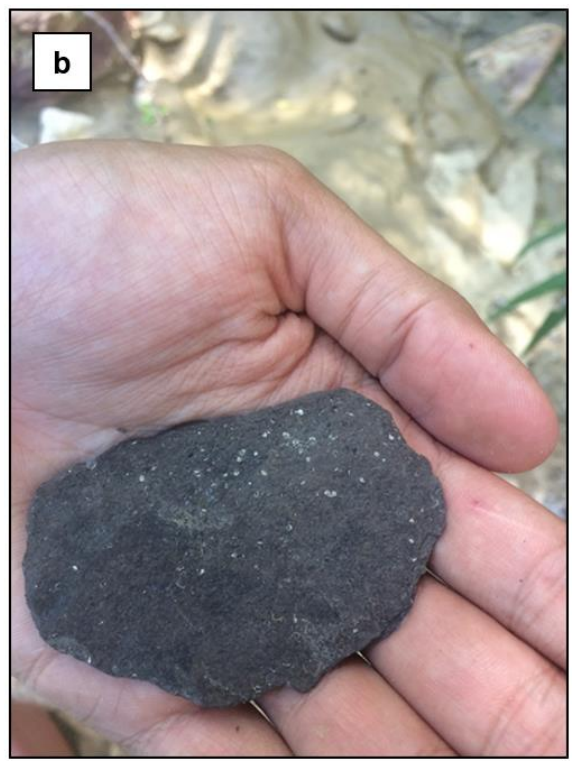

Figura 15 - (a) Fragmentos de folhelhos verdes correspondentes à Formação Romualdo; (b) Ocorrência de fragmentos orgânicos com a presença de ostracodas. 


\section{Formação Exu}

Composta por arenitos contendo grânulos e seixos de quartzo, nãoorientados, imersos em uma matriz de composição arcoseana cimentada por óxi-hidróxido de ferro (Fig. 16). As rochas ocupam uma região mais inclinada na escapa norte da Bacia do Araripe, marcando o platô da chapada.

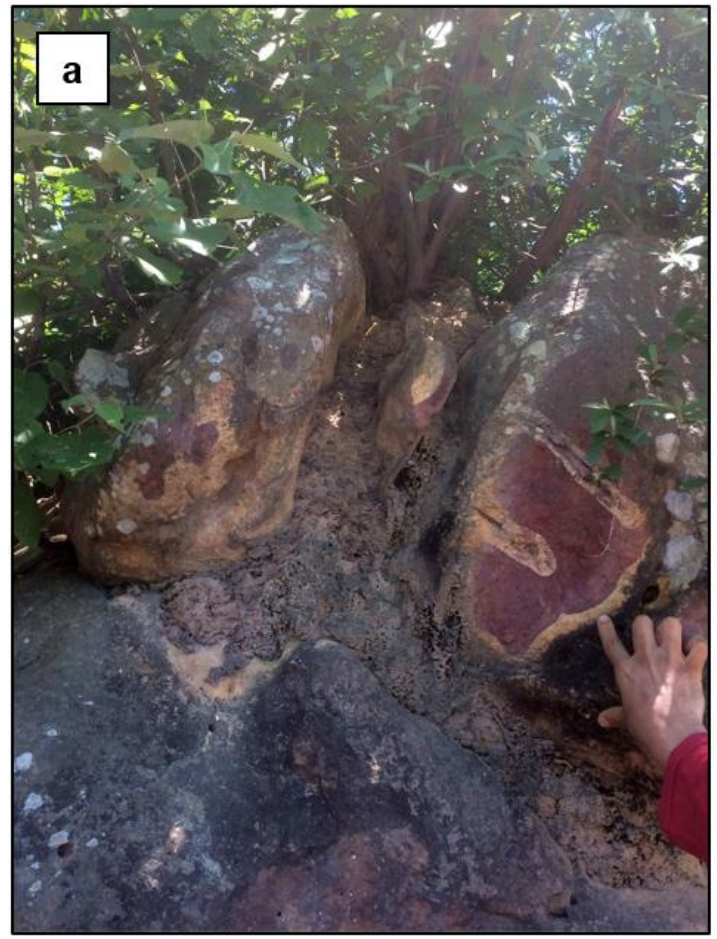

Apesar de exibida no Mapa Geológico do Estado do Ceará (Cavalcante et al., 2003), não foi identificada em campo a Formação Araripina, cuja melhor exposição está localizada na borda sul da Bacia do Araripe, de acordo com Assine (2007). Desta forma, foi inferido contato direto entre as formações Romualdo e Exu.

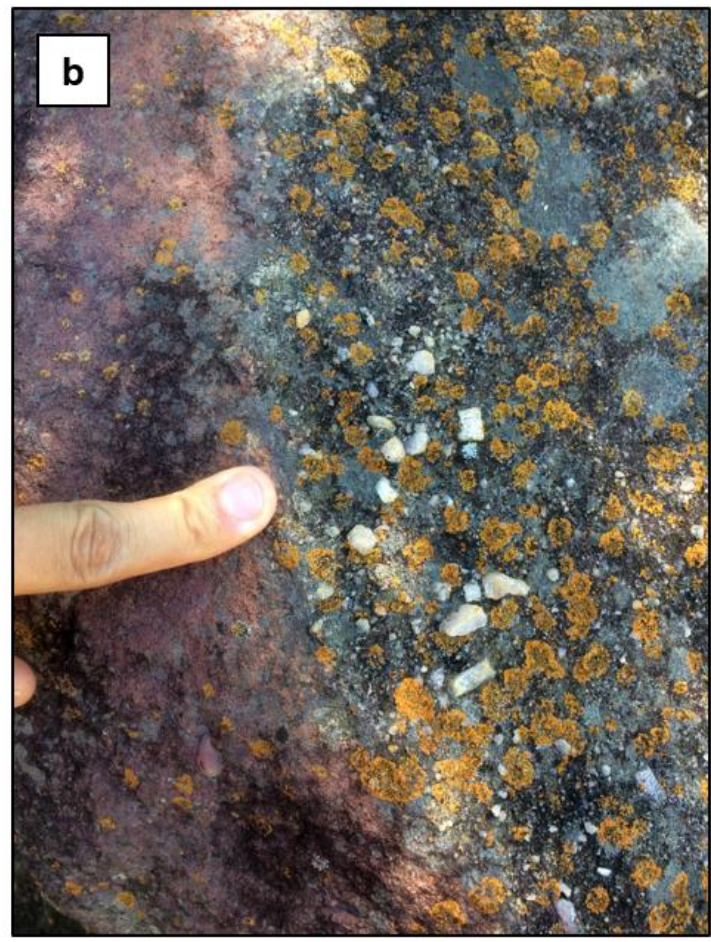

Figura 16 - (a) Blocos soltos da Formação Exu, com porções brancas nos arenitos devido à lixiviação de óxi-hidróxidos de ferro, formando auréolas de remoção do cimento em torno de porções avermelhadas ainda mais preservadas; (b) Grãos de quartzo subarredondados a ângulosos não-orientados imersos em uma matriz arcoseana cimentada por óxi-hidróxido de ferro.

\section{Depósitos Aluviais}

Constituídos por terrenos argilosos, por vezes alagados, e gretas de contração, acompanhando as maiores drenagens na área, sendo relacionados às planícies de inundação do Riacho Grande e do Rio Cariús (Fig. 17). Localmente, parecem sofrer influência também da Formação Mauriti, formando pequenos bolsões coluviais com fragmentos conglomeráticos.

A variação abrupta na direção das drenagens que contornam a Formação Mauriti sugere um controle estrutural nesta porção, com variação de um trend NW-SE para NE-SW, padrão compatível com os lineamentos topográficos identificados por Miranda (2015), o que pode sugerir influência neotectônica na estruturação destas feições. Neste 
contexto, Oliveira et al. (2019) investigaram a atividade neotectônica na borda norte da Bacia do Araripe por meio da integração de índices morfométricos, observando que a região entre os municípios de Nova Olinda e

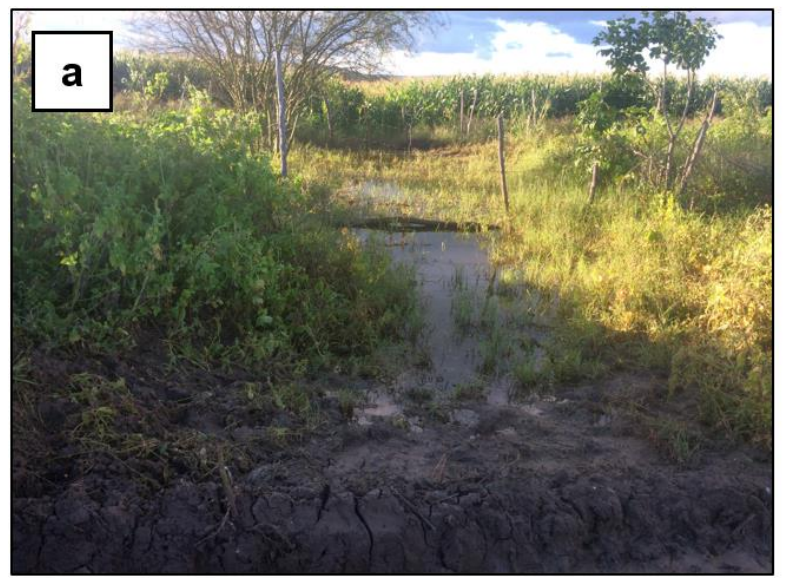

Santana do Cariri apresenta indícios de atividade tectônica alta.

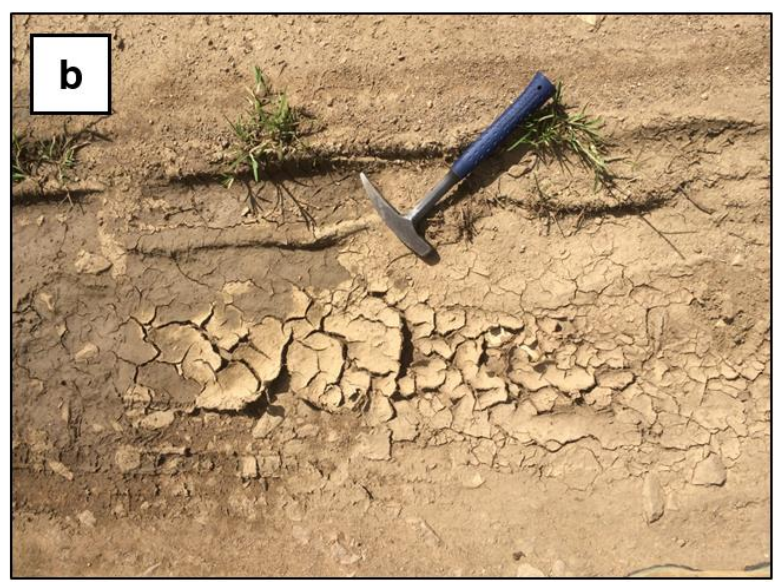

Figura 17 - Aspecto geral dos depósitos aluviais na área em estudo, apresentando porções argilosas mais escuras (a) e gretas de contração (b).

\section{CONSIDERAÇÕES FINAIS}

A área de estudo apresentou contextos típicos já conhecidos do empilhamento estratigráfico da Bacia do Araripe. Porém, algumas feições como a presença de fraturas preenchidas por calcita e texturas indicativas sismitos sugerem uma possível influência tectônica no contexto deposicional da Formação Crato.

A identificação de padrões de drenagens com mudanças bruscas de direção sugere uma forte influência de sistemas de fraturas que podem ser do embasamento) na área, além de auxiliar na delimitação das unidades litoestratigráficas.

Apesar da não identificação in situ de alguns litotipos, como a Formação Ipubi, o mapeamento geológico caracterizou esta porção da borda norte da Bacia do Araripe, contribuíndo propiciando um melhor entendimento de seu contexto deposicional e pósdeposicional e servindo como base para a execução de futuros trabalhos mais aprofundados na região. Neste contexto, sugere-se o aprofundamento nos estudos sobre a influência neotectônica na estruturação da região.

\section{Agradecimentos}

Os autores agradecem ao Departamento de Geologia, ao Laboratório de Geoprocessamento do Ceará (GEOCE) e ao Programa de PósGraduação em Geologia da Universidade Federal do Ceará pela estrutura fornecida para a realização deste trabalho, além da Coordenação de Aperfeiçoamento de Pessoal de Nível Superior (CAPES) e ao Conselho Nacional de Desenvolvimento Científico e Tecnológico (CNPq) pela concessão de bolsa de pesquisa sob o processo $n^{\circ}$ 134165/2019-5. 


\section{REFERÊNCIAS}

Assine, M. L. 2007. Bacia do Araripe. Boletim de Geociências da Petrobras, 15 (2): 371-389.

Assine, M. L; Perinotto, J. A. J.; Custódio, M. A.; Neumann, V. H.; Varejão, F. G.; Mescolotti, P. C. 2014. Sequências deposicionais do andar Alagoas da Bacia do Araripe, nordeste do Brasil. Boletim de Geociências da Petrobras, 22 (1): 3-28.

Barros, S. D. S; Santos, R. B.; Horn, B. L. D.; Rocha, D. E. G. A.; Amaral, C. A. 2017. Projeto Gesso na Bacia do Araripe, Noroeste de Pernambuco, NE do Brasil. In: $27^{\circ}$ SIMPÓSIO DE GEOLOGIA DO NORDESTE, João Pessoa, 2017. Anais, João Pessoa.

Beurlen, K. 1962. A geologia da Chapada do Araripe. Anais da Academia Brasileira de Ciências, 34 (3): 365-370.

Brito Neves, B. B; Santos, E. J.; Van Schmus, W. R. 2000. Tectonic history of the Borborema Province, Northeastern Brazil. In: Cordani, U. G.; Milani, E.J.; Thomaz Filho, A.; Campos, D. A. (ed.). Tectonic Evolution of South America. Rio de Janeiro, $31^{\circ}$ International Geological Congress, 31, p. 151-182.

Cavalcante, J. C.; Vasconcelos, A. M.; Medeiros, M. D. F.; Paiva, I. G.; Gomes, F. E. M.; Cavalcante, S. N.; Cavalcante, J. E.; Melo, A. C. R.; Duarte Neto, V. C.; Benevides, H. C. 2003. Mapa geológico do Estado do Ceará - Escala 1:500.000. Fortaleza, Ministério das Minas e Energia/Companhia de Pesquisa de Recursos Minerais (CPRM).

Chagas, D. B. D. 2006. Litoestratigrafia da Bacia do Araripe: reavaliação e propostas para revisão. Programa de Pós-Graduação em Geologia Regional, Instituto de Geociências e Ciências Exatas, Universidade Estadual Paulista, Dissertação de Mestrado, 127p.

Gaspary, J.; Anjos, N.F.R. 1964. Estudo Hidrogeológico de Juazeiro do Norte-Ceará. Superintendência do Desenvolvimento do Nordeste, Divisão de Documentação.

Miranda, T. S. D. 2015. Caracterização geológica e geomecânica dos depósitos carbonáticos e evaporíticos da Bacia do Araripe, NE Brasil. Programa de PósGraduação em Geociências, Universidade Federal de Pernambuco, Tese de Doutorado, 269p.

Oliveira, V. F.; Silva Filho, W. F.; Neto, J. D. A. N. 2019. Atividade neotectônica na borda norte da Bacia do Araripe (Ceará-Brasil): Evidências a partir de índices morfométricos. Geociências (São Paulo), 37 (3): 523-541.

Ponte, F. C.; Appi, C. J. 1990. Proposta de revisão da coluna litoestratigráfica da Bacia do Araripe. In: CONGRESSO BRASILEIRO DE GEOLOGIA, 36, Natal, 1990. Anais, p. 211-226.

Silva, H. A.; Alencar, M. L.; Carrino, T. A.; Barbosa. J. A.; Oliveira, P. F. P. 2017. Utilização de imagem multiespectral do sensor ASTER para identificação de calcita e gipsita na Bacia do Araripe - CE. In: XVIII SIMPÓSIO BRASILEIRO DE SENSORIAMENTO REMOTO (SBSR), Santos, 2017. Anais, INPE, p. 7134-7141.

SUDENE, BRASIL. 1969. Ministério do Exército. DSG. Santana do Cariri. Rio de Janeiro, $62 \times 74 \mathrm{~cm}$. Folha SB.24-Y-D-11. Escala 1:100.000. $7^{\circ} 00^{\prime}-7^{\circ} 30^{\prime} \mathrm{S}, 39^{\circ} 30^{\prime}-40^{\circ} 00^{\prime} \mathrm{W}$. 